El Plan de Salud de Navarra 2001-2005

Navarra Health Plan 2001-2005

\title{
S. Cervera
}

La acción planificadora en materia sanitaria -mediante el establecimiento de orientaciones, fines y objetivos-, resalta hoy día como una exigencia inherente a los sistemas de salud del mundo desarrollado. Por una parte, la necesidad de prever la mejor utilización de los medios en la gestión de los recursos disponibles, y por otra, la obligatoria adaptación e incorporación racional que debe realizarse de los avances de la ciencia y la tecnología sanitaria, hacen que sea un requisito ineludible el enunciar y llevar a término documentos como este segundo Plan de Salud de Navarra. Más allá de la mera obligación legal, la responsabilidad en la administración pública sanitaria impone la elaboración de modelos de planificación como el que nos ocupa, expresión de una forma de trabajar en el futuro conforme a las expectativas que la propia sociedad sea capaz de asumir, conseguir y legitimar.

Diez años después de la aprobación del primer Plan de Salud de la Comunidad Foral, el Departamento de Salud del Gobierno de Navarra ha podido elaborar este segundo enmarcado en unas condiciones bien diferentes. En aquel entonces, Navarra se enfrentaba al desarrollo de las competencias sanitarias, y ello confería a aquel ejercicio planificador un cierto componente pionero. El reto era entonces tanto la mejora de las condiciones de salud de la población navarra como el afianzamiento de un modelo de administración más cercana y capacitada. El primer Plan de Salud recogía, al igual que lo hace éste, las aportaciones y recomendaciones que la Organización Mundial de la Salud establecía para el área europea, y reconocía la existencia de múltiples factores condicionantes del estado de salud individual y poblacional. Sería injusto no reconocer ahora la importancia que tuvo aquel primer plan, y la aportación que ha dejado en nuestra sociedad a través de la consolidación del actual modelo sanitario, que ha avanzado mucho en la extensión de la adhesión e identificación del conjunto de nuestra población hacia sus fines, capacidades y realidades.

\section{Un plan para una sanidad madura}

Este nuevo Plan de Salud nace para actuar dentro de una realidad madura y arraigada de nuestra sanidad. Los últimos años han sido especialmente decisivos en la consolidación de las posibilidades del sistema de salud, mediante realidades como la culminación del proceso de implantación de la moderna atención primaria, la valoración de las capacidades técnico-asistenciales de los dispositivos de salud pública, la mejora tecnológica e infraestructural de lo sanitario, el 
rodaje de nuevas modalidades de gestión en los centros y la incorporación decidida de líneas de formación e investigación en nuestros profesionales. De otra parte, asistimos a un momento en el que el hecho asistencial se ve condicionado cada vez más por la propia disponibilidad del conocimiento, con la importancia que tiene saber discernir entre la accesibilidad de la información y la aplicabilidad y utilidad real de la ciencia consecuente.

Es por esto por lo que este Plan de Salud nace con la intención de ser eminentemente efectivo y veraz. No se pretende con este texto enunciar una mera declaración de intenciones, o diseñar un futuro de arcadia feliz en materia sanitaria. Por el contrario, en la medida en que pretende operar sobre la realidad del Sistema de Salud, aparece como un ejercicio de rigor intelectual en la propia valoración de sus fines y contenidos. Este es, ciertamente, un plan que se quiere caracterizar por su componente práctico y realista, por la capacidad que adquiere de mejorar de manera contrastable el actual estado de los servicios sanitarios que se ofrecen a las personas y con ello obtener resultados de salud individuales y colectivos.

El diseño seguido es relativamente novedoso en el conjunto de planes de salud de nuestra nación. La selección de las cinco áreas prioritarias de actuación, y la enunciación solvente y sistematizada de las actuaciones necesarias para abordar la reducción del impacto de las patologías correspondientes, hacen que la construcción conceptual de este plan sea la que merece una sanidad madura como es la nuestra. A partir de ahí, el logro de los objetivos marcados en el desarrollo estratégico de las medidas propuestas es algo que deberá abarcar y comprometer a toda la organización sanitaria, cuya finalidad esencial es el servicio en la lucha contra la enfermedad y en la mejora de la salud de las personas.

Desde esta perspectiva es como mejor se comprende que éste sea además un "plan de planes". Recoge propuestas que singularmente hubieran sido necesarias para cada una de las cinco áreas de actuación previstas, pero les añade el valor de incluirlas dentro del conjunto de las prioridades de la organización sanitaria, cuanto de avalarles en los términos de análisis de evidencia y racionalidad planificadora que ha impregnado todo el conjunto. También por esta razón, el presente Plan de Salud enlaza con un conjunto de actuaciones estratégicas ya en desarrollo en nuestra sanidad, a través de diversos planes y programas que en él se integran y reconocen.

\section{Mejorando el sistema de valores}

Sería muy limitada una visión de este Plan que sólo quisiera entenderlo como una descripción de actividades planificadas. La base de su construcción no sólo estriba en el análisis de la evidencia disponible sobre las posibles prestezas sanitarias y la correspondiente propuesta de actuación para los próximos años; la auténtica raíz conceptual de este Plan se establece mediante la propuesta que incorpora de asunción de nuevos valores sociales en el desarrollo de nuestra sanidad. También aquí, en sentido evolutivo, cabe definir una época previa en la que el alcance de la universalidad y la equidad de las prestaciones sanitarias eran no sólo la prioridad, sino seguramente el hecho mas característico de la intención social sobre la sanidad. En la medida en la que esos postulados ya están insertos en 
los títulos legales y en la voluntad de la ciudadanía, hemos de dar paso a un grado mayor de compromiso de Navarra para con su Sistema de Salud.

Los conceptos de corresponsabilidad, calidad y eficiencia basada en el coste-efectividad de las intervenciones sanitarias son los verdaderos protagonistas de nuestro futuro en esta materia. La sociedad cambia y a través del cambio de los valores que interioriza se deben armonizar también los cambios de actitudes en los dispositivos por los que se expresa el sistema de salud. La corresponsabilidad es una mejor definición del principio de solidaridad y universalidad que a todos nos incumbe; la calidad es hoy una exigencia cierta de los pacientes a los que hay que atender profesionalmente; la eficiencia es el soporte del sostenimiento y trascendencia intergeneracional de nuestro actual sistema sanitario. Con la incorporación de estos principios se pretende generar un modelo más solvente de mejora de las capacidades de nuestra sanidad, y convertirla en el centro de las políticas de bienestar que nuestra sociedad quiera merecer en su realidad inmediata. Acompasar la búsqueda de la mayor efectividad y calidad sanitaria con la conciencia de los medios que Navarra debe disponer para ello es uno de los objetivos implícitos más importantes de este Plan.

Recójase, por fin, este Plan como un compromiso del conjunto de la sociedad para con el futuro más saludable de las personas. No es un marco que comprometa sólo las actuaciones del sistema público, ni una propuesta teorética del estado actual del conocimiento y la evidencia científica. Por el contrario, debe valorarse como un ámbito de compromiso de la sanidad en su conjunto con las personas, y de estas con su sanidad. Ese encuentro, productivo y esperanzador desde el mayor de los realismos, es lo que tras estas páginas deberíamos encontrar.

$$
\begin{gathered}
\text { Cuiniono Cll } \\
\text { Santiago Cervera Soto } \\
\text { Consejero de Salud } \\
\text { Gobierno de Navarra }
\end{gathered}
$$

Agosto 2001 